\title{
UM OLHAR GEOGRÁFICO SOBRE A EDUCAÇÃO AMBIENTAL EMPRESARIAL NO SUPERMERCADO PÃO DE AÇÚCAR, TERESINA PI
}

\author{
Valdinéia de Santana Santos Alves ${ }^{1}$
}

\begin{abstract}
RESUMO
A grande preocupação das empresas atuais é desenvolver atividades e práticas em Educação Ambiental que atendam à sustentabilidade e ao meio ambiente, bem como às exigências legais $e$ às regulamentações governamentais no cumprimento de suas responsabilidades sociais e ambientais. Dessa forma, este trabalho teve como objetivo analisar a prática e a contribuição da Educação Ambiental na empresa Pão de Açúcar em Teresina - PI para a Sustentabilidade do meio ambiente. Na busca pelo alcance dos objetivos propostos utilizou-se de um conjunto de procedimentos metodológicos, quantitativos e qualitativos, a saber: levantamento bibliográfico em livros e artigos; pesquisa documental em documentos fornecidos pela empresa; observação in loco; e pesquisa de campo, com a realização de registros fotográficos e aplicação de questionários. Os resultados da pesquisa apontam para a prática de Educação Ambiental baseada nos princípios da sustentabilidade e é notável a participação dos funcionários nos programas voltados para a Sustentabilidade e Educação Ambiental, porém a empresa se mostra pouco eficiente no sentido de desenvolver cursos e palestras, que possam contribuir para a formação dos funcionários na área de Educação Ambiental.
\end{abstract}

Palavras-chave: Geografia. Educação Ambiental Empresarial. Sustentabilidade.

\footnotetext{
${ }^{1}$ Universidade Estadual do Piauí - UESPI. E-mail: neinhasrn23@hotmail.com
} 


\begin{abstract}
The great concern of the current companies is to develop activities and practices in environmental education that meet the sustainability and the environment, as well as legal requirements and Government regulations in compliance with its social and environmental responsibilities. Thus, this study aimed to analyze the practice and the contribution of environmental education in the company Pão de Açúcar in Teresina-PI for the sustainability of the environment. In the pursuit of achieving the proposed objectives used a set of methodological, quantitative and qualitative procedures, namely: bibliographic survey in books and articles; documentary research on documents provided by the company; observation on the spot; and field research, with photographic records and questionnaires. The survey results point to the practice of environmental education based on the principles of sustainability and is notable for the participation of the staff in programs focused on sustainability and environmental education, however the company shows little efficient to develop courses and lectures, which could contribute to the training of employees in the area of environmental education.
\end{abstract}

Keywords: Geography. Corporate Environmental Education. Sustainability.

\title{
1 INTRODUÇÃO
}

A Educação Ambiental vem assumindo crescente importância na sociedade, principalmente pela urgência de reversão do quadro de degradação ambiental que ocorre em muitos países em todo o mundo. A Educação Ambiental Empresarial como uma prática socioeducativa fornece informações para que haja a conscientização ambiental, comprometimento e a participação da população aliada aos gestores das empresas, com a finalidade de estabelecer um processo permanente para conhecer e minimizar a problemática ambiental.

Esse estudo teve como objetivo geral analisar a prática e a contribuição da Educação Ambiental na empresa Pão de Açúcar em Teresina - PI para a Sustentabilidade do meio ambiente. E como objetivos específicos: Identificar as iniciativas de redução dos impactos sobre o meio ambiente causados pela operação da empresa Pão de Açúcar em Teresina, Piauí; investigar dados sobre os possíveis Programas ambientais implantados na empresa.

Na década de 1970, como relata Guimarães (1995, p. 17), "podemos perceber como as discussões fora do país, apresentadas em conferências 
internacionais, refletem-se neste processo de definição do que é a EA". Assim, em nível mundial, a questão ambiental ganhou grande repercussão com a Conferência das Nações Unidas para o Meio Ambiente, realizada em Estocolmo, sendo discutida também nesta conferência a questão da educação para o meio ambiente.

$\mathrm{Na}$ década em questão, as discussões em torno do meio ambiente foram de extrema importância, pois se pensava em métodos de compreensão da temática ambiental nas ciências de um modo geral, inclusive na Geografia. Sobre essa questão, Lima (1984, p. 18) comenta que, com o desdobramento de Estocolmo, aconteceu em Belgrado o Seminário Internacional sobre a Educação Ambiental, o qual "explicitou as metas e os objetivos da Educação Ambiental, onde o princípio básico é a atenção com o meio natural e artificial".

Em 1977, a ONU, através da Unesco, organizou a I Conferência Intergovernamental sobre Educação para o Ambiente, em Tbilisi na Geórgia (ex-União Soviética). Nessa reunião, em seu documento final, foram tratados de forma mais sistemática e com uma abrangência mundial as diretrizes, as conceituações e os procedimentos da Educação Ambiental. Kein (1984 apud GUIMARÃES, 1995, p. 19) destaca as conclusões e recomendações desse documento, a seguir, algumas delas: "separar o mito do homem sobre a natureza [...] estar atentos para a manipulação publicitária. [...] uma nova ética que rejeitasse a exploração, o consumismo e a exaltação da produção como fim por si só".

No intuito de ampliar as discussões sobre os problemas ambientais em 1992, os líderes de quase todas as nações do mundo para a Conferência das Nações Unidas sobre o Meio Ambiente e Desenvolvimento, conhecida popularmente como a "Cúpula da Terra" ou "ECO-92. Com a organização da ECO-92, a Educação Ambiental estabeleceu-se perante a sociedade brasileira, criando uma forte demanda institucional. Muitos projetos em Educação Ambiental estavam sendo desenvolvidos, ainda de forma pouco sistematizada (GONÇALVES, 1990).

A Conferência das Nações Unidas sobre Desenvolvimento Sustentável Rio+20, que ocorreu no ano de 2012, ficou assim conhecida, porque marcou os vinte anos de realização da Conferência das Nações Unidas sobre Meio 
Ambiente e Desenvolvimento (ECO-92) e, contribuiu para definir a agenda do desenvolvimento sustentável para as próximas décadas.

A Rio+20 priorizou o desenvolvimento sustentável e, é inegável a evolução de um movimento global, isso por ter obtido a presença de representantes de vários países. Trouxe a renovação e reforçou o compromisso político para o desenvolvimento sustentável nas nações.

Existem dispositivos legais no Brasil que seguindo uma tendência mundial, dão importância para a educação ambiental. A Política Nacional de Meio Ambiente (1981) já apontava para a necessidade de a Educação Ambiental ser oferecida em todos os níveis de ensino. Brasil (1988, art. 225) estabelece que todos tivessem direito ao meio ambiente ecologicamente equilibrado, impondo-se ao Poder Público e à coletividade o dever de defendêlo e preservá-lo para às presentes e futuras gerações; assegura a efetividade desse direito, incumbe ao Poder Público: promover a Educação Ambiental em todos os níveis de ensino e a conscientização pública para a preservação do meio ambiente.

No Brasil, em 27 de abril de 1999 foi sancionada a Lei Federal no 9.795 que institui a Política Nacional de Educação Ambiental - PNEA. Nela são definidos os princípios relativos à Educação Ambiental que deverão ser seguidos em todo o Brasil.

De acordo com a Política Nacional de Educação Ambiental, por Educação Ambiental entendem-se os processos por meio dos quais o indivíduo e a coletividade constroem valores sociais, conhecimentos, habilidades, atitudes e competências voltadas para a conservação do meio ambiente, bem de uso comum do povo, essencial à sadia qualidade de vida e sua sustentabilidade (BRASIL, 1999).

No que se refere à Educação Ambiental Empresarial, a mesma é disciplinada pela lei 9.795 de 27 de Abril de 1999, a qual foi regulamentada em 25 de Junho de 2002, através do decreto $n \times 4.281$ que traz no inciso $V$ do art. $3^{\circ}$ a seguinte incumbência: "Às empresas, entidades de classe, instituições públicas e privadas, promover programas destinados à capacitação dos trabalhadores, [...] bem como sobre as repercussões do processo produtivo no meio ambiente" (BRASIL, 1999, p. 1). 
A Política Ambiental de uma organização é um documento que estabelece, direciona, orienta e dá suporte às ações de cunho ambiental necessárias ao desempenho das empresas, de modo que as mesmas estejam em conformidade com as normas e legislações aplicáveis. Neste sentido, um sistema de gestão ambiental visa atender determinados requisitos para que a organização esteja em conformidade com as normas pertinentes.

Leff $(2009$, p.) afirma que o discurso do Desenvolvimento Sustentável não é homogêneo. Pelo contrário, expressa estratégias conflitivas que respondem a visões e interesses diferenciados. A perspectiva economicista privilegia o livre mercado como mecanismo para internalizar as externalidades ambientais e para valorizar a natureza, recodificando a ordem da vida e da cultura em termos de um capital natural e humano.

Antes da implementação da EA no processo de Gestão Ambiental, a abordagem deve ocorrer no âmbito teórico, juntamente com a apresentação de práticas onde os funcionários e o público externo possam visualizar e compreender os possíveis benefícios a serem obtidos, bem como os impactos negativos que poderão ser evitados.

A análise periódica da efetividade das práticas torna-se um instrumento importante no processo, pois verifica se o projeto está atingindo seu objetivo. Com a implantação da EA na empresa, as comunidades devem ser comunicadas dos benefícios obtidos com as ações do Sistema de Gestão Ambiental. Segundo Pedrini (2008), a Educação Ambiental Empresarial Brasileira - EAEB é ainda limitada às empresas de grande porte e tem se restringido à academia e aos órgãos de controle ambiental.

Em uma empresa a Educação Ambiental pode conduzir os profissionais a uma grande mudança de comportamento e atitudes em relação ao meio ambiente podendo alcançar uma transformação profunda dos funcionários ao presidente, sobre questões como o uso inteligente dos recursos naturais, condições mais seguras sob o aspecto ambiental para os operários, redução das infrações ambientais e destinação final adequada do lixo reciclável e no não reciclável.

De acordo com (ALMEIDA, 2002, p. 25) "no universo empresarial, a dimensão ambiental era vista, na melhor das hipóteses, como um mal necessário". No ambiente empresarial as questões ambientais eram colocadas 
apenas para cumprir regrar estabelecidas, ou seja, as empresas não conseguiam obter lucratividade através das atividades e práticas sustentáveis, nem tampouco com a Educação Ambiental.

O conhecimento geográfico conduz a uma ciência de inter-relações. Moreira (2002, p. 74) afirma que "o homem e a natureza formam uma unidade orgânica”, que está sendo rompida pelo caráter agressivo do homem sobre a natureza e o meio, o que gera problemas ambientais ligados à conservação dos recursos naturais. O debate teórico entre a Geografia e a Educação Ambiental está traçado com o meio natural e sua relação com a sociedade.

De acordo com Sansolo e Cavalheiro (2006) a relação entre a Geografia e a Educação Ambiental Empresarial pode ser feita através de um aprofundamento nas vertentes da Geografia. No entanto, é necessário trazer as reflexões para a relação homem-natureza. Assim, é impossível de se desvincular o homem do estudo da natureza, dessa maneira, especificamente para a Geografia, não haveria sentido em se estudar a natureza desvinculada do homem.

Segundo Gil (2001, p.35) "O ambiente dinâmico das organizações requer o desenvolvimento de ações voltadas à constante capacitação dos indivíduos, com vista em torná-los mais eficientes naquilo que fazem". Assim, a Geografia aplicada ao espaço das empresas pode ser vista não só pela questão dos espaços e dos fluxos a serem estudados pela Geografia, mas também na valorização da Educação Ambiental, que envolva uma formação e qualificação proposta aos funcionários e colaboradores por meio do treinamento e da educação ambiental corporativa.

\section{METODOLOGIA}

Na realização da pesquisa foi utilizada a pesquisa bibliográfica em livros e periódicos, utilizou-se uma abordagem do tipo qualitativa e a sistematização dos dados ocorreu de forma dedutiva. A pesquisa documental através de registros escritos que proporcionou o levantamento de informações em prol da compreensão dos fatos e relações, ou seja, possibilitam conhecer o período histórico e social das ações a e reconstruir os fatos e seus antecedentes, pois 
se constituem em manifestações registradas de aspectos da vida social de determinado grupo (OLIVEIRA, 2007).

Através também da observação, que exige uma sistematização prévia (roteiro de observação) que deve focar os objetivos da investigação, a fim de fundamentar o planejamento de estratégias para o melhor desenvolvimento das ações no âmbito estudado (QUEIROZ et al., 2007); e dos dados obtidos pela aplicação dos métodos e técnicas escolhidos para a pesquisa de campo deste trabalho, que se mostraram como técnicas eficazes, complementares e úteis para subsidiar os estudos pretendidos.

O público alvo escolhido para a realização da pesquisa foram os funcionários e o gestor do supermercado Pão de Açúcar. Através de entrevistas estruturadas direcionadas a 30 (trinta) funcionários, que foram abordados aleatoriamente devido à ocupação de cada um, sendo que foram respondidas apenas 20 .

A realização da pesquisa de campo foi feita através de quatro visitas ao supermercado. Durante a primeira visita, houve um diálogo com 0 representante da empresa sobre qual seria a contribuição da mesma para a realização da pesquisa; nas duas visitas posteriores foram feitas as entrevistas com os funcionários e o representante legal da empresa; e na quarta visita foram feitos os registros fotográficos, os quais demonstram a estreita relação da empresa com a Educação Ambiental e a veracidade dos dados, e por fim os agradecimentos aos que participaram e contribuíram para a realização da pesquisa de campo. A localização do Supermercado Pão de Açúcar, fica no cruzamento entre as avenidas Homero Castelo Branco e Dom Severino, bairro de Fátima, na zona Leste da cidade de Teresina - PI. 
Figura (1) - Localização do objeto de estudo

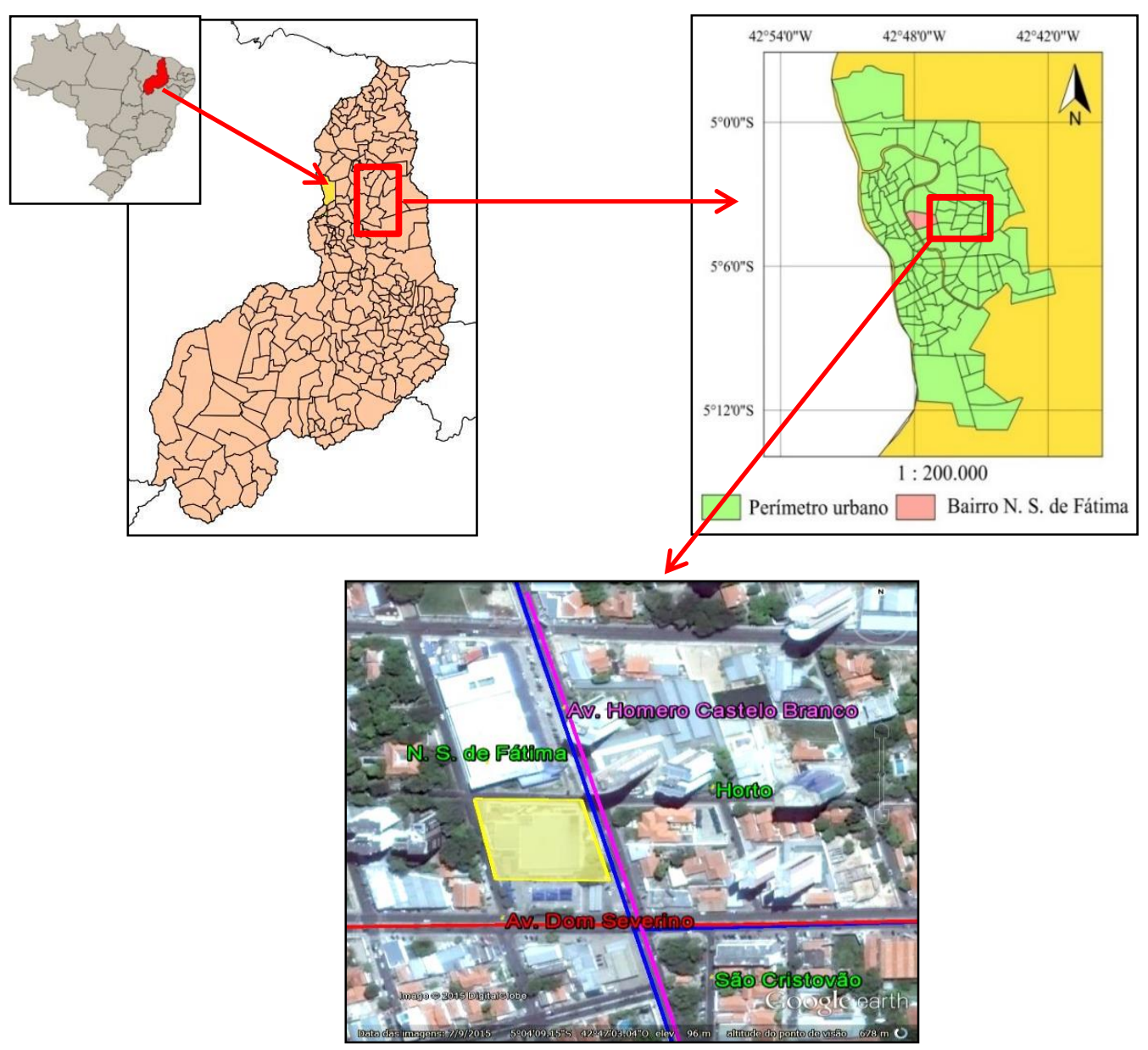

Supermercado Pão de Açúcar — Limite dos bairros Fonte: IBGE/Google earth, 2015. Org: SENA, N. A.

\section{A EDUCAÇÃO AMBIENTAL NO SUPERMERCADO PÃO DE AÇÚCAR}

Os documentos disponibilizados para análises foram selecionados em função do objetivo central da pesquisa: Identificar as concepções e práticas de Educação Ambiental desenvolvidas no supermercado Pão de Açúcar. Para tanto, após o início do trabalho de campo, buscamos relacionar os possíveis documentos que entendemos ser necessários para o desenvolvimento deste trabalho. Foram analisados documentos adquiridos em diversas formas, tais como: meios eletrônicos e documentos de treinamento sobre as questões ambientais. Algumas solicitações de documentos que tratam sobre a educação ambiental e treinamento do público interno não foram disponibilizados. Restou- 
nos então analisar apenas os documentos eletrônicos que foram fornecidos pelo Grupo Pão de Açúcar através de e-mail.

Buscamos então, relacionar as atividades de Educação Ambiental e de Sustentabilidade praticadas pelo supermercado, os dados e informações contidas nos respectivos documentos: o Relatório Anual e de Sustentabilidade (2014) do Grupo Pão de Açúcar, que cita a sustentabilidade como eixo estratégico trazendo o diálogo e o avanço da plataforma de gestão sustentável, definindo os compromissos socioambientais.

Traz como meta a continuação e a sequência das ações de educação ambiental voltadas para logística reversa de resíduos dos clientes, por meio da expansão das estações de reciclagem e de campanhas de comunicação; o Relatório do 1ำ Prêmio FGV - EAESP de Responsabilidade Social no Varejo (2003), fala sobre as estações de reciclagens como ferramentas de inclusão social através da geração de emprego e renda associada as atividades de coletas, como forma de promover a Educação Ambiental dos clientes e das comunidades que vivem no entorno do supermercado e promover também a conscientização dos clientes para as questões ambientais.

\subsection{Educação Ambiental e papel dos funcionários no Supermercado Pão de açúcar}

O questionário aplicado aos funcionários (Apêndice A) destacava algumas perguntas que além de buscar o conhecimento de documentos que tratam da Educação Ambiental, buscam também confrontar as atividades sobre a Educação Ambiental.

A Tabela 1 abaixo mostra que no que diz respeito à escolaridade dos entrevistados, o Ensino Médio é o nível de escolaridade predominante, cerca de $60 \%$ dos entrevistados, Seguido pela Graduação (35\%). Alguns funcionários, em conversa informal, alegaram a interrupção dos estudos devido ao fato de terem que trabalhar para ajudar suas famílias. Entre os participantes da pesquisa não houve nenhum que possuísse apenas o Ensino Médio, ou que já fosse mestrando ou doutorando. 
Tabela 1 - Escolaridade dos entrevistados

\begin{tabular}{l|c|c}
\hline Escolaridade & № de entrevistados & $\%$ \\
\hline Ensino Médio & 12 & 60 \\
Graduação & 7 & 35 \\
Especialização & 1 & 5 \\
\hline Total & 20 & 100 \\
\hline
\end{tabular}

Fonte: Santana, 2015.

De acordo com Oliveira (2001, p. 12), "O processo formal de educação dentro das empresas é chamado de treinamento." Nesse sentido, além da necessidade de promover informações relativas aos conhecimentos sobre a área ambiental, será dada maior ênfase no treinamento que possibilite mudança de atitude por parte dos gestores e funcionários. $O$ treinamento e a educação ambiental dentro da empresa permitem, que juntos possam desenvolver um adequado comportamento ambiental em suas atividades diárias.

Quando questionados sobre o tempo de trabalho na empresa pão-deaçúcar os funcionários participantes da pesquisa, em sua maioria, responderam de 6 a 10 anos de trabalho (45\%); sendo que $20 \%$ possuem um ano e menos de um ano, e 15\% apenas possuem mais de 10 anos (Gráfico 1).

Gráfico 1 - Tempo de trabalho dos entrevistados

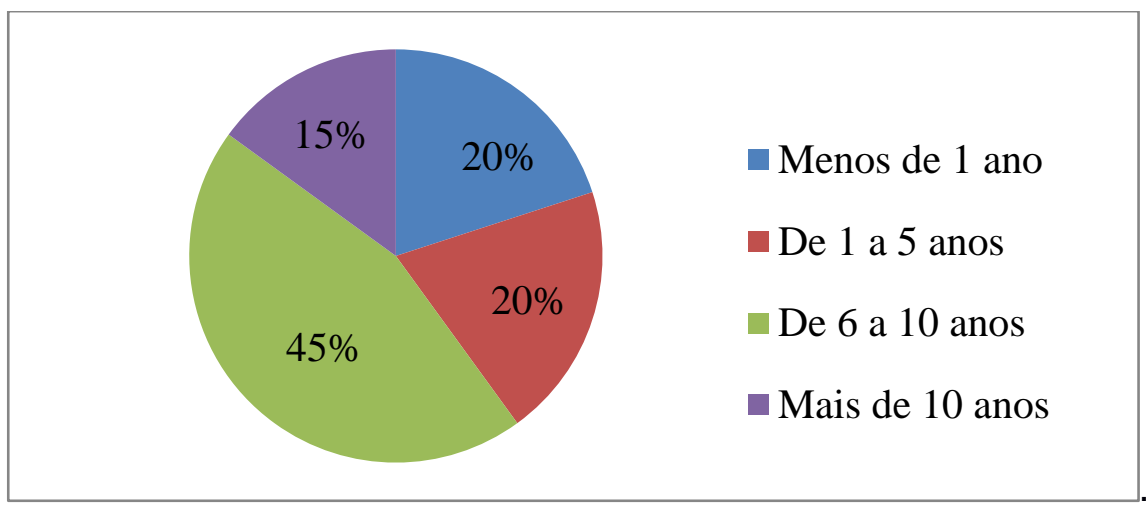

Fonte: Santana, 2015.

De acordo com a gerente de recursos humanos do supermercado Pão de Açúcar, o motivo pelo qual os funcionários possuem um tempo de serviço 
significativo ocorre devido às condições de trabalho corresponder às suas expectativas.

O supermercado Pão de Açúcar traz um leque de colaboradores em diversas áreas. Sendo assim, a tabela 2 ilustra os cargos ocupados pelos funcionários entrevistados. É possível observar o destaque aos líderes de seção, estes representam $25 \%$ e possuem a função de liderança e orientação das atividades em equipe, acompanham processos e produtividade da área e elaboram relatórios de acompanhamento dos resultados.

Seguindo a análise da tabela 2 , temos $15 \%$ dos entrevistados representando os operadores de supermercado, cuja função é zelar pelo desempenho do departamento, garante o abastecimento dos produtos e frutas, e orienta os consumidores; Também representado por $15 \%$ estão os funcionários que operam os caixas, principal agente no supermercado para a concretização do programa caixa verde, pois as caixas são ligadas a cada caixa de pronto atendimento.

Ainda na tabela 2, os entrevistados dos cargos de fiscal de loja/perdas (seguranças), analista de processamento de dados (Controla o fluxo de informações na empresa) e auxiliar administrativo (assistente da área administrativa) representam 10\% cada; E os cargos de consultor de clientes (atendimento aos clientes para esclarecimento de dúvidas), cartazista (confecção de anúncios) e fiscal de caixa (presta assistência aos operadores de caixa) representando cada $5 \%$ dos entrevistados.

Tabela 2 - Cargo dos entrevistados

\begin{tabular}{l|c|c}
\hline Cargo dos entrevistados & № de entrevistados & $\%$ \\
\hline Líder seção & 5 & 25 \\
Operador & 3 & 15 \\
supermercado & & 15 \\
Operador de caixa & 3 & 10 \\
Fiscal de lojaslperdas & 2 & 10 \\
Processamento de dados & 2 & 10 \\
Auxiliar administrativo & 2 & 5 \\
Consultor de clientes & 1 & 5 \\
Cartazista & 1 & 5 \\
Fiscal de caixa & 1 & 100 \\
\hline Total & 20 &
\end{tabular}


As exigências nas atividades de Sustentabilidade e Educação Ambiental na empresa recaem sobre os indivíduos que ocupam os vários tipos de cargos e funções, procurando desenvolver suas atribuições, e as habilidades que tem ou que devem ser desenvolvidas e adquiridas, para que possam contribuir para a condução adequada dessas atividades dentro do supermercado Pão de Açúcar.

Dentre os vários conceitos existentes sobre o que é educação ambiental, a Conferência Sub-regional de Educação Ambiental para a Educação Secundária, que aconteceu no Peru em 1976, considerou a Educação Ambiental uma ação educativa permanente pela qual a comunidade educativa tem a tomada de consciência de sua realidade global, do tipo de relações que os homens estabelecem entre si e com a natureza, dos problemas derivados de ditas relações e suas causas profundas (GUIMARÃES, 1995). Assim ao serem questionados sobre $O$ entendimento acerca do conceito de Educação Ambiental os funcionários em sua maioria (85\%) escolheram respostas que tinham palavras como: consciência, ação, estudo e meio ambiente (Tabela 3).

Tabela 3 - Entendimento sobre educação ambiental

\begin{tabular}{l|c|c}
\hline $\begin{array}{l}\text { O que você entende por educação } \\
\text { ambiental }\end{array}$ & $\begin{array}{c}\text { № de } \\
\text { entrevistados }\end{array}$ & \% \\
\hline Consciência sobre os problemas ambientais & 7 & 30 \\
$\begin{array}{l}\text { Ação voltada para a proteção do meio } \\
\text { ambiente }\end{array}$ & 6 & 20 \\
$\begin{array}{l}\text { Estudo voltado para melhoria do meio } \\
\text { ambiente }\end{array}$ & 4 & 15 \\
Não sabiam & 3 & 100 \\
\hline Total & 20 & \\
\hline
\end{tabular}

Fonte: Santana, 2015.

No supermercado Pão de Açúcar, onde foi realizada a pesquisa, é inegável o conhecimento de todos sobre o envolvimento da empresa com a 
Educação Ambiental e a Sustentabilidade. Assim, segundo Wouterlood (2010), a Educação Ambiental Empresarial funciona como mecanismo necessário na criação de condições para que esses funcionários atuem na transformação da realidade e principalmente por contribuir para o desenvolvimento do senso de responsabilidade, por meio da participação ativa na prevenção e solução de problemas socioambientais.

Segundo Almeida (2003) os gerentes das empresas devem entender que a Terra é finita, que sua capacidade de recuperação do uso excessivo de recursos é limitada e que as pressões para as empresas modificarem seu comportamento vão aumentar. Essas restrições serão inexoráveis e, por isso, as empresas têm que se antecipar a esses desafios aplicando ao mercado o conhecimento ambiental nascido nos laboratórios.

Os processos de educação e formação ambiental desempenham um papel fundamental e promovem a participação de todos os setores na tomada de decisões dentro de uma empresa, entretanto, apesar de conhecerem a Educação Ambiental, 95\% dos funcionários não possuem formação na área, conforme mostra a tabela 4.

Tabela 4 - Formação em educação ambiental

\begin{tabular}{l|c|c}
\hline Possui formação em educação ambiental & $\begin{array}{c}\text { № de } \\
\text { entrevistados }\end{array}$ & $\%$ \\
\hline Não & 19 & 95 \\
Sim & 1 & 5 \\
\hline Total & 20 & 100 \\
\hline
\end{tabular}

Fonte: Santana, 2015.

Segundo Motta (2010), um programa de Educação Ambiental não pode ficar restrito a um programa de treinamento visando à sensibilização e motivação dos funcionários, e sim atuar de forma ativa no próprio posto de trabalho dos operadores. Durante a realização da pesquisa foi observado à atuação dos funcionários no supermercado pão de açúcar, sendo notáveis suas participações nos programas voltados para a sustentabilidade e Educação Ambiental, porém a empresa se mostra pouco eficiente no sentido de desenvolver cursos e palestras, que possam contribuir para a formação dos 
funcionários na área de Educação Ambiental.

Ao serem questionados sobre as suas participações nas atividades de Educação Ambiental promovidas pela empresa (tabela 5) a maioria respondeu que "sim" (55\%), e citaram atividades como palestras, treinamentos dentre outras. Os $45 \%$ restantes informaram não participarem das atividades de Educação Ambiental da Empresa.

Tabela 5 - participação nas atividades de educação ambiental na empresa

\begin{tabular}{l|c|c}
\hline Participação nas atividades & № de entrevistados & $\%$ \\
\hline Sim & 11 & 55 \\
Não & 9 & 45 \\
\hline Total & 20 & 100 \\
\hline
\end{tabular}

Fonte: Santana, 2015

Segundo Almeida (2002), para uma empresa se tornar sustentável ela precisa de comando e controle, auto regulação e instrumentos de mercado, mas diz que o mecanismo que equilibra e dá estabilidade a uma empresa sustentável é saber ouvir e levar em consideração em suas decisões às opiniões de todas as partes interessadas - indivíduos, instituições, comunidades e outras empresas que com ela interagem. Trata-se de aceitar além dos donos e acionistas. A empresa precisa dialogar com os empregados e suas famílias. Sendo assim, pode-se perceber no supermercado pão-deaçúcar o engajamento da empresa com seus funcionários.

A informação sobre desenvolvimento sustentável ultrapassa a teoria e, através do trabalho da grande maioria, chegam à prática. A tabela 6 mostra 0 total de funcionários que foram informados sobre o desenvolvimento sustentável e sobre empresa sustentável, onde 70\% receberam informações sobre desenvolvimento sustentável e empresa sustentável, enquanto $30 \%$, ainda, não receberam tais informações. 
Tabela 6 - Informações sobre desenvolvimento sustentável e empresa sustentável

\begin{tabular}{l|c|c}
\hline Informações & № de entrevistados & $\%$ \\
\hline Sim & 14 & 70 \\
Não & 6 & 30 \\
\hline Total & 20 & 100 \\
\hline
\end{tabular}

Fonte: Santana, 2015.

As informações sobre desenvolvimento sustentável e empresa sustentável foram passadas aos funcionários através de palestras e treinamentos fornecidos pela empresa. De acordo com o representante do supermercado - essas palestras e treinamentos foram realizados, principalmente, quando a empresa iniciou suas atividades de Sustentabilidade e Educação Ambiental, e que por esse motivo alguns funcionários, que possuem de um a dois anos de serviços, não obtiveram informações acerca dessas atividades através de palestras e treinamentos, contudo, seguem orientações da gerência da empresa.

Quanto à contribuição que as práticas de educação ambiental desenvolvidas pelo supermercado pão de açúcar podem exercer na vida das pessoas, os entrevistados não tiveram dúvidas, em sua maioria, citaram a questão da melhoria das condições socioambientais locais (31,3\%). Acreditam também em abordagens como a contribuição para a conscientização das questões ambientais (17,2\%). Não tiveram dúvidas, também, ao afirmarem que a Educação Ambiental torna clientes e funcionários atuantes na sociedade $(10,3 \%)$, através do alcance que as ações de conscientização e treinamento oferecem no desenvolvimento dos seus sensos críticos (Tabela 7). 
Tabela 7 - Contribuições da educação ambiental praticada na empresa

\begin{tabular}{lc|c}
\hline Contribuições da EA & № de respostas & $\%$ \\
\hline $\begin{array}{l}\text { Melhora as condições socioambientais } \\
\text { locais }\end{array}$ & 9 & 31,3 \\
$\begin{array}{l}\text { Contribui p\a consciência das questões } \\
\text { ambientais }\end{array}$ & 5 & 17,2 \\
$\begin{array}{l}\text { Torna clientes e funcionários atuantes na } \\
\text { sociedade }\end{array}$ & 3 & 10,3 \\
$\begin{array}{l}\text { Crescimento profissional dos funcionários } \\
\text { Desenvolve o senso crítico da sociedade }\end{array}$ & 2 & 6,9 \\
$\begin{array}{l}\text { Transforma a vida dos funcionários e } \\
\text { cliente }\end{array}$ & 2 & 6,9 \\
Acredita em todas as opções & 2 & 6,9 \\
\hline Total & 6 & 20,5 \\
\hline Fonte: Santana, 2015 & \multicolumn{2}{|c}{} \\
\end{tabular}

Sendo assim entende-se que a Educação Ambiental praticada no supermercado Pão de Açúcar pode contribuir para a melhoria das habilidades para lidar com a sustentabilidade, além de promover informações relacionadas ao meio ambiente para a sociedade. Outro aspecto que pode contribuir é o desenvolvimento e o incentivo à conscientização ambiental, para que se tenha uma melhoria nas condições ambientais locais.

Nessa perspectiva Carvalho (1998, p. 24) traz seu ponto de vista sobre a contribuição da Educação Ambiental, quando diz que "a formação de uma atitude ética e política é a grande contribuição que a Educação Ambiental pode dar num mundo em crise como o que vivemos".

Nos resultados da pesquisa pode-se observar que as práticas de Educação Ambiental na empresa, na visão dos funcionários, valorizam a interação com as comunidades do entorno (54\%), ou seja, a comunidade é o principal público alvo das práticas de Educação Ambiental do supermercado pão de açúcar. Isso se deve ao fato de que essas comunidades podem colaborar para a melhoria do meio ambiente utilizando a Estação de 
Reciclagem e o coletor de pilhas e baterias, que se encontram à disposição no supermercado.

Ainda de acordo com a resposta dos funcionários $16,6 \%$ das práticas são destinadas a clientes da empresa; 12,5\% aos funcionários do supermercado e $16,6 \%$ a outros públicos, tais como fornecedores, consumidores, meios de comunicação, organismos do Poder Público, prestadores de serviços, acionistas e concorrentes (gráfico 2).

Gráfico 2 - Público alvo das práticas de educação ambiental

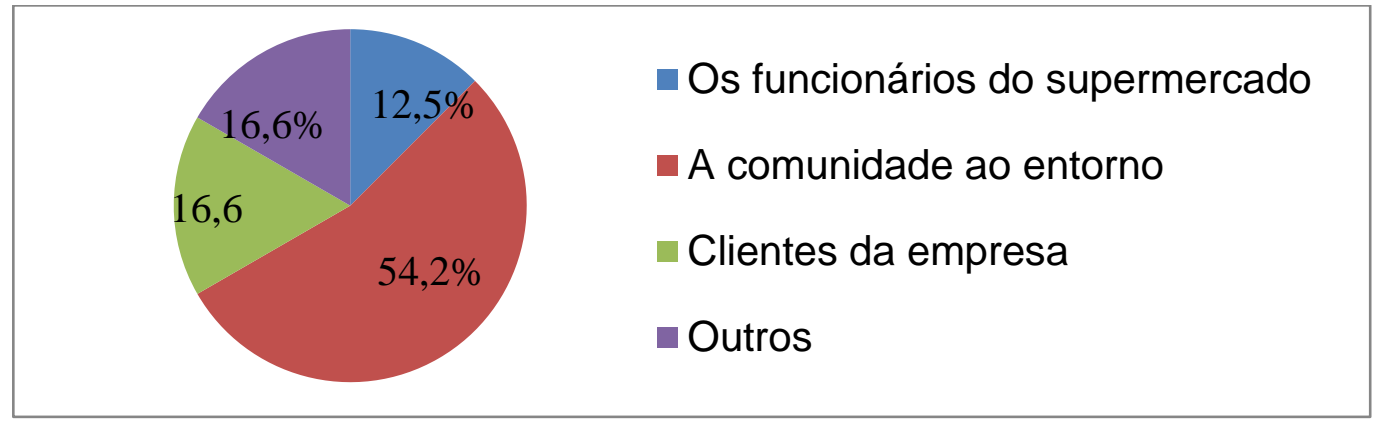

Fonte: Santana, 2015.

As Estações de Reciclagem do Pão de Açúcar, em parceria com a Unilever, foram lançadas há seis anos, já estão presentes em 89 lojas Pão de Açúcar e tornaram-se referências por sua eficiência, sustentabilidade e responsabilidade socioambiental com a coleta de embalagens pós-consumo. Desde 2001, já foram recolhidas 14.800 toneladas de plásticos, papéis, metais, alumínios e vidros, o que representa a impressionante média mensal de 322 toneladas. (ver figura 1 e 2).

Figura 2 - Estação de ReciclagemlFachada

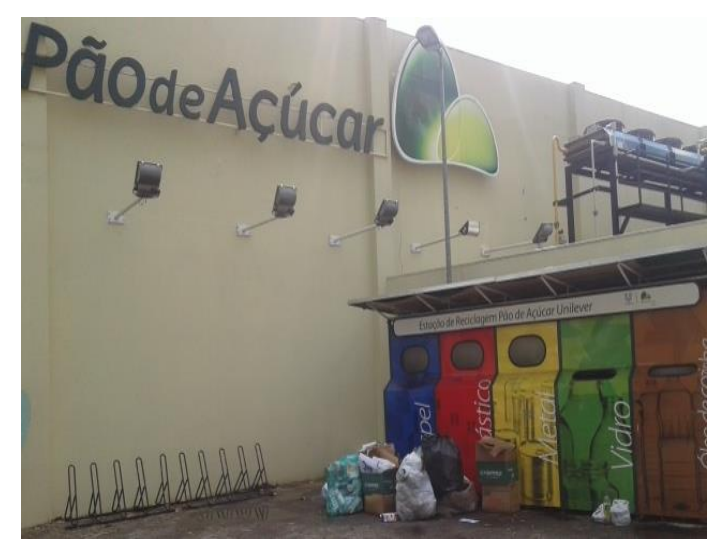


Figura 3 - Estação de Reciclagem

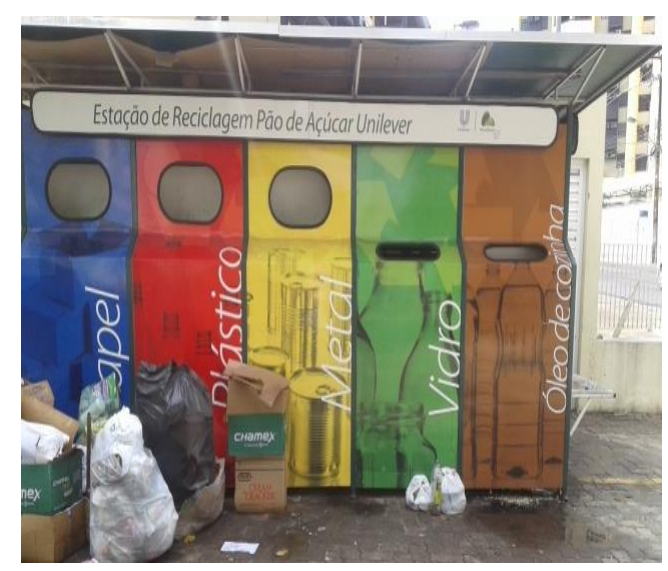

Fonte: Santana, 2015.

O programa Estação de Reciclagem Pão de Açúcar Unilever destina-se a promover a educação e conscientização ambiental, incentivando a reciclagem de embalagens pós-consumo por meio da instalação de pontos de coleta seletiva nas lojas, contribuindo para a inclusão social das pessoas que dele participam. O Programa responde, assim, à urgente necessidade de envolver as comunidades nas ações de preservação ambiental, por meio da mudança de hábitos e costumes individuais e coletivos. É, também, uma forma de a empresa assumir a sua responsabilidade quanto à recuperação e reciclagem de embalagens por ela comercializadas que, em geral, os consumidores descartam no meio ambiente, com graves consequências presentes e futuras.

O programa Estação de Reciclagem Pão de Açúcar Unilever é uma parceria inovadora, entre empresas líderes: os Supermercados Pão de Açúcar, a primeira no ranking da Associação Brasileira de Supermercados (ABRAS) e a Unilever, a maior fabricante de produtos de consumo do Brasil. Alinhada a outras iniciativas de ambas as empresas nas áreas ambientais e do consumo consciente, o Relatório Prêmio FGV - EAESP de Responsabilidade Social no Varejo (2003) elenca os principais objetivos das Estações de Reciclagem Pão de Açúcar Unilever: 
- Promover a educação ambiental dos clientes e das comunidades que vivem nos arredores das lojas, de maneira orientada para a coleta seletiva e a reciclagem de embalagens pós-consumo;

- Conscientizar as comunidades para a questão ambiental, estimulando a adoção de novos hábitos individuais e coletivos, que contribuam para a preservação de um meio ambiente mais saudável;

- Promover a inclusão social por meio da geração de emprego e renda associada a atividades de coleta, separação, enfardamento de resíduos recicláveis, como papéis, vidros e plásticos;

- Conscientizar clientes do Pão de Açúcar e as comunidades do entorno das lojas para reintegrar à cadeia produtiva os materiais coletados e separados, evitando o seu descarte no meio ambiente;

- Implantar, executar e aperfeiçoar modelos de negócios que respondam a demandas sociais, econômicas e ambientais, disseminando e estimulando a replicação das experiências (PRÊMIO FGV-EAESP, 2003, p. 10).

Segundo Almeida (2003) os gerentes das empresas devem entender que a Terra é finita, que sua capacidade de recuperação do uso excessivo de recursos é limitada e que as pressões para as empresas modificarem seu comportamento vão aumentar. Segundo os dados obtidos nos questionários aplicados aos funcionários do supermercado Pão de Açúcar, esta é considerada muito importante por $85 \%$ dos entrevistados, e importante para $15 \%$; para as demais variáveis (pouco importante, sem importância e outros) não se obteve nenhum resultado (Tabela 8 ).

Tabela 8 - A importância da educação ambiental praticada pela empresa

\begin{tabular}{l|c|c}
\hline Nível de Importância & № de entrevistados & $\%$ \\
\hline Importante & 3 & 15 \\
Muito importante & 17 & 85 \\
\hline Total & 20 & 100 \\
\hline
\end{tabular}

Fonte: Santana, 2015.

O Sistema de Gestão Ambiental no supermercado Pão de Açúcar exige dos funcionários da empresa, desde o mais alto cargo ao mais simples, uma constante integração e organização que reflete em todos os setores e também nas atividades, trazendo mudanças de comportamento na vida dos funcionários.

Sendo assim, de acordo com as respostas obtidas e expostas na tabela 9, às atividades de Educação Ambiental praticada pelo supermercado Pão de Açúcar desperta as pessoas para as questões ambientais (30\%), trazem o 
crescimento como ser social (5\%) e fornece subsídios para transformar e melhorar as condições socioambientais (10\%). Para 55\% dos entrevistados todas as opções citadas são de grande relevância para as mudanças de comportamento.

Tabela 9 - Mudanças no comportamento adquirida através da educação ambiental

\begin{tabular}{l|c|c|}
\hline Mudanças & $\begin{array}{c}\text { № de } \\
\text { entrevistados }\end{array}$ & $\%$ \\
\hline Desperta para as questões ambientais & 6 & 30 \\
Traz o crescimento como ser social & 1 & 5 \\
Fornecer subsídios para melhoria das condições & 2 & 10 \\
socioambientais & 11 & 55 \\
Acredita em todas as opções & 20 & 100 \\
\hline Total & & \\
\hline
\end{tabular}

Fonte: Santana, 2015

As mudanças de comportamento adquiridas através da Educação Ambiental, de acordo com Leão e Silva (1999) busca a consciência crítica que permita o entendimento e a intervenção de todos os setores da sociedade, encorajando o surgimento de um novo modelo de sociedade, onde a preservação dos recursos naturais seja compatível com o bem-estar sócio econômico da população.

\subsection{A fala do representante do Supermercado Pão de açúcar}

O Ambiente Empresarial é quase sempre carente de tempo. São muitas as tarefas e decisões. Durante a realização desta pesquisa foi observado que os funcionários, e, principalmente aqueles que ocupam cargos de chefia, supervisão ou gerência, encontram-se quase sempre sobrecarregados de serviços e envolvidos com tarefas de maior prioridade, exigindo assim por parte de nós pesquisadores, persistência e objetividade. 
Através da análise da entrevista direcionada ao representante do supermercado Pão de Açúcar foi possível obter resultados significativos. A entrevista foi introduzida com o questionamento sobre o seu tempo de serviço na empresa. O representante informou que - "são 26 anos de dedicação". Com pouco entusiasmo falou do grau de escolaridade o qual ela considera ser baixo (ensino superior incompleto).

Segundo dados coletados na entrevista com o gestor, o supermercado Pão de Açúcar desenvolve atividades voltadas para a Educação Ambiental há 6 (seis) anos. Durante esse período foram feitas palestras e treinamentos com os funcionários, contudo alguns deles já saíram da empresa, e recentemente não foram realizados treinamentos com os novos funcionários, mas todos receberam e recebem orientações acerca das atividades realizadas pelo supermercado.

De acordo com o gestor, a Educação Ambiental praticada pelo supermercado Pão de Açúcar segue e atende princípios estabelecidos por alguns documentos, tais como: a Política Nacional do Meio Ambiente, que estabelece em parágrafo único, que as atividades empresariais públicas ou privadas serão exercidas em consonância com as diretrizes da Política Nacional do Meio Ambiente; o Pacto Global, que é uma iniciativa da Organização das Nações Unidas - ONU de engajamento do setor privado na condução de seus negócios por meio de alguns valores nas áreas de direitos humanos, relações de trabalho e meio ambiente; o supermercado pão de açúcar é associado do Instituto Ethos, que tem como missão mobilizar, sensibilizar e ajudar as empresas a gerir seus negócios de forma socialmente responsável, tornando-as parceiras na construção de uma sociedade justa e sustentável;

Assim como todo o Grupo Pão de Açúcar, a unidade do supermercado em que foi realizada a pesquisa é associada ao Compromisso Empresarial para Reciclagem (Cempre), que tem como objetivos promover a reciclagem pós-consumo e difundir a Educação Ambiental com foco na teoria dos três Rs (Reduzir, Reutilizar e Reciclar).

O representante do supermercado Pão de Açúcar acredita que a Educação Ambiental pela empresa contribui para muitos fatores relevantes, 
mas, principalmente, para tornar clientes e funcionários atuantes na sociedade atual.

Quanto ao público alvo das práticas de Educação Ambiental no supermercado pão de açúcar, este respondeu que são os clientes.

Entre projetos de Educação Ambiental desenvolvido pela empresa está - Programa Estações de Reciclagem Pão de Açúcar Unilever. Segundo informações coletadas na empresa o Pão de Açúcar foi à primeira rede de varejo a disponibilizar pontos de entrega voluntária de materiais recicláveis (plástico, papel, metal, vidro, óleo de cozinha usado) nas suas lojas.

Tudo que é arrecadado é doado para cooperativas de reciclagem parceiras do programa. O Programa Caixa Verde (ver figura 3) é uma iniciativa inédita de reciclagem pré-consumo. Esse programa consiste no descarte de embalagens secundárias que não precisam ser levadas para casa, as caixas verdes ficam instaladas na saída dos caixas. O Programa já está presente em $100 \%$ das lojas do Brasil. Ao todo, já foram recolhidas e doadas para as cooperativas de reciclagem parceiras mais de 4,2 milhões de embalagens.

Figura 4 - Programa caixas verde

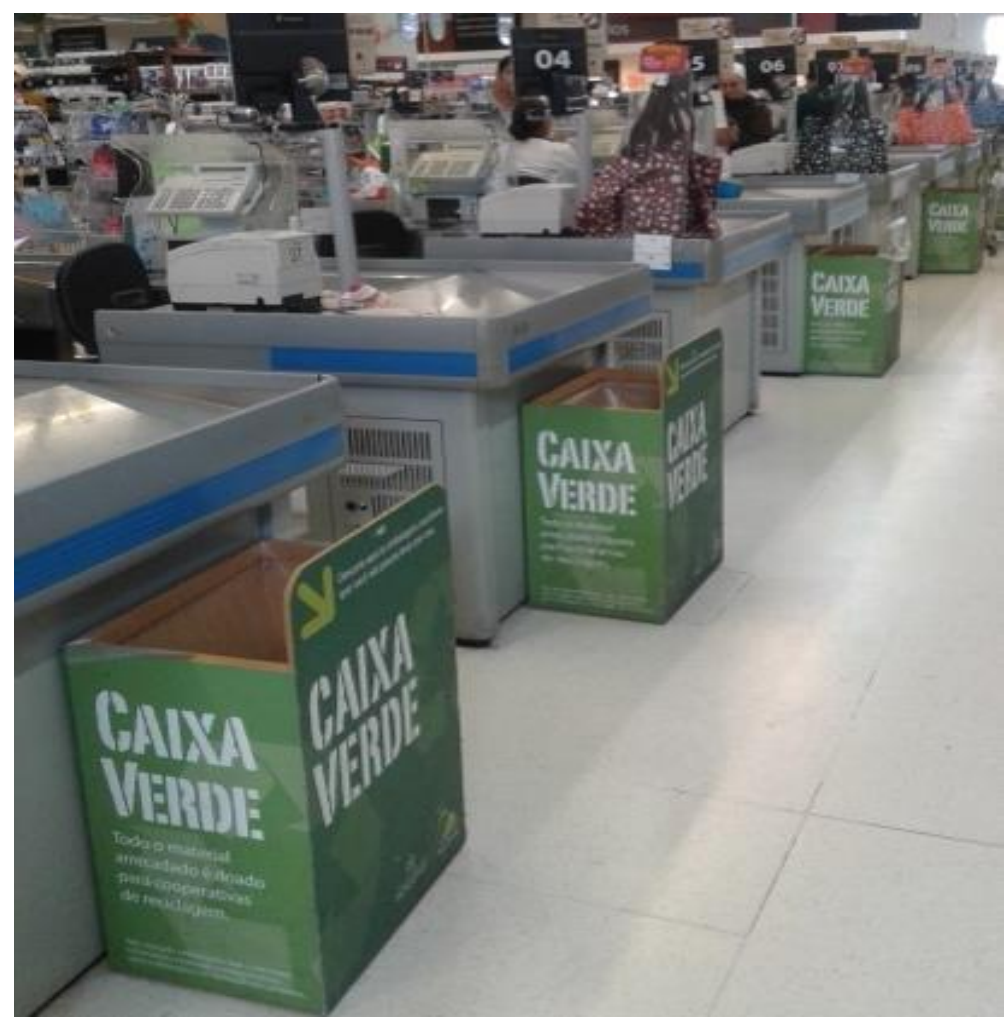

Fonte: Santana, 2015. 
Outro programa existente é o Alô Recicle (ver figura 5), que em parceria com a Nókia do Brasil tem como objetivo a logística reversa de aparelhos de telefone celular e materiais relacionados, como baterias e acessórios. O Pão de Açúcar, em parceria com a Fundação SOS Mata Atlântica, oferece uma alternativa prática e ecologicamente correta para os consumidores embalarem suas compras: as sacolas retornáveis (ver figura 6). Levando a sacola retornável sempre que for às compras, o consumidor contribui com a redução do lixo gerado diariamente com sacolas descartáveis e, como consequência, com a diminuição da demanda pela produção de materiais plásticos.

Figura 5 - Alô Recicle sacolas retornáveis

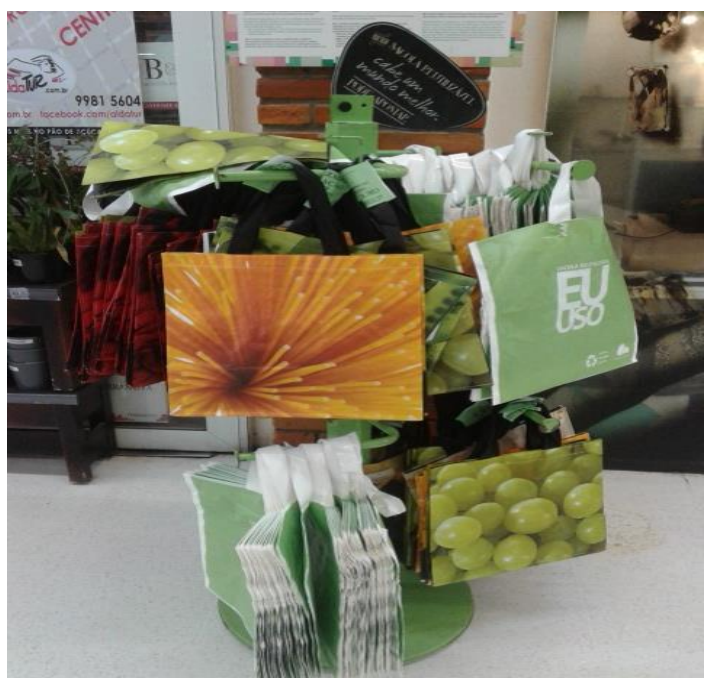

Fonte: Santana, 2015.
Figura 6 - Demonstrador de

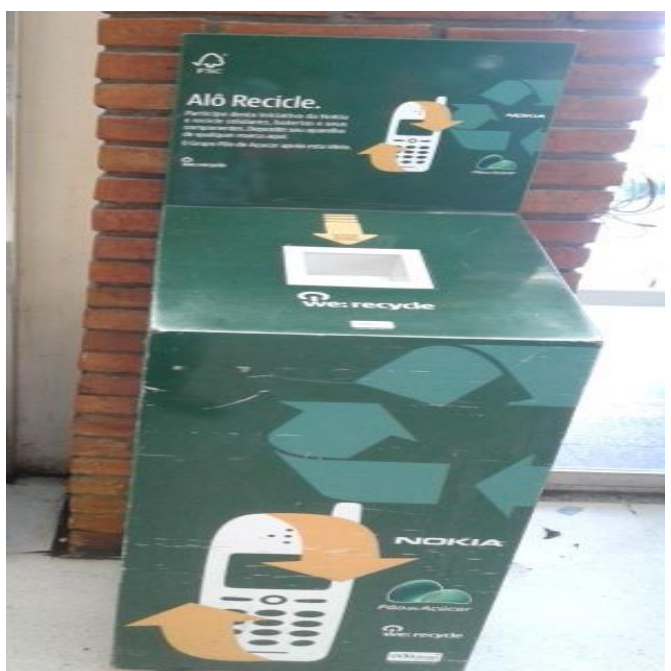

Fonte: Santana, 2015

O projeto Alô Recicle se tornou uma iniciativa que auxilia na eliminação de pilhas e baterias que antes era descartado de forma errada. Já a venda de sacolas retornáveis se tornou uma alternativa prática para os clientes transportarem suas compras em substituição às sacolas plásticas.

A Educação Ambiental é uma atividade que deve ser planejada e executada por todos os gestores de uma empresa, contando com o empenho de todos os setores, tanto humano quanto administrativo da empresa ou indústria, com a finalidade de alcançar um resultado que possa combinar as necessidades individuais com as necessidades organizacionais. De acordo com Roos e Becker (2012, p. 864) “a educação ambiental é a base cientifica para a sustentabilidade, sendo que a sustentabilidade é um processo que 
deverá atingir a sociedade como um todo, sem excluir nenhum elemento físico, mental ou espiritual desse processo de transformação".

Influenciando diretamente nas ações e práticas do supermercado Pão de Açúcar, e tentando manter um padrão de relacionamento entre seus públicos de interesse em prol da sustentabilidade e Educação Ambiental, o quadro 1 abaixo mostra os resultados da entrevista com o representante do supermercado Pão de Açúcar, onde buscou-se integrar as informações, envolvendo a sua esfera de atuação, desde a postura de gestão até as práticas relacionadas ao meio ambiente realizadas pela empresa.

Quadro 1 - Resultado da entrevista com o representante da empresa Pão de

Açúcar

\begin{tabular}{|c|c|}
\hline Questionamentos & Respostas do Representante \\
\hline Tempo de serviço & 26 anos \\
\hline Formação & Superior incompleto \\
\hline $\begin{array}{l}\text { Há quanto tempo o supermercado } \\
\text { pão de açúcar desenvolve } \\
\text { atividades em EA }\end{array}$ & Aproximadamente 6 anos \\
\hline $\begin{array}{l}\text { Importância da prática da EA pela } \\
\text { empresa }\end{array}$ & Muito importante \\
\hline $\begin{array}{l}\text { A empresa atende a princípios de } \\
\text { quais documentos }\end{array}$ & $\begin{array}{l}\text { Política Nacional de Meio Ambiente, } \\
\text { Pacto Global e Instituto Ethos }\end{array}$ \\
\hline Sobre o plano de gestão ambiental & Possui \\
\hline $\begin{array}{l}\text { Contribuição da EA praticada pela } \\
\text { empresa }\end{array}$ & $\begin{array}{l}\text { Torna clientes e funcionários atuantes } \\
\text { na sociedade }\end{array}$ \\
\hline $\begin{array}{l}\text { Público alvo das práticas de EA na } \\
\text { empresa }\end{array}$ & Clientes da empresa \\
\hline $\begin{array}{l}\text { Incentivo para funcionários } \\
\text { desenvolverem atividades de EA } \\
\text { fora da empresa }\end{array}$ & Sim (não justificado) \\
\hline $\begin{array}{l}\text { Projetos de EA que foram } \\
\text { desenvolvidos pela empresa }\end{array}$ & $\begin{array}{l}\text { Caixas-verdes, coletor de pilhas e } \\
\text { baterias, estação de reciclagem, } \\
\text { sacolas retornáveis }\end{array}$ \\
\hline
\end{tabular}

Fonte: Santana, 2015.

Durante a pesquisa foi constatado que o Grupo Pão de Açúcar se preocupa com o meio ambiente e busca equilibrar questões econômicas, sociais e ambientais, alinhadas aos princípios de Educação para o Consumo e Gestão Eficiente, tendo em vista o desenvolvimento de programas de 
educação ambiental que enfatizam o consumo e o descarte consciente. São várias ações e iniciativas que visam difundir o conceito de crescimento sustentável entre os públicos de relacionamento: colaboradores, comunidade, sociedade, cliente, acionistas e fornecedores.

\section{CONSIDERAÇÕES FINAIS}

Nossos objetivos permearam buscar as atividades de Educação Ambiental praticadas pelo supermercado pão de açúcar, e se as mesmas seguem ou atendem princípios estabelecidos pelos documentos, programas e políticas existentes para promover a preservação do meio ambiente.

A política ambiental do supermercado pão de açúcar faz menção à Educação Ambiental relacionada aos princípios, à responsabilidade e compromisso dos empregados com o desempenho ambiental. Aliada à implementação do Sistema de Gestão Ambiental, o supermercado pão de açúcar mantém iniciativas que visam minimizar os impactos de sua operação sobre o meio ambiente com o objetivo de atender à Política Nacional de Meio Ambiente, ao pacto Global e ao Instituto Ethos.

Vale ressaltar que mesmo a pesquisa revelando que $85 \%$ dos funcionários entrevistados possuem um entendimento sobre o conceito de educação ambiental, foi possível notar que apenas 55\% deles participam das palestras e treinamentos, sobre a Educação Ambiental, oferecidos pela Empresa. Entretanto, estes, acreditam que a prática da educação ambiental traz melhorias nas condições socioambientais locais, contribui na conscientização das questões ambientais, tornando clientes e funcionários sujeitos críticos e atuantes na sociedade.

A empresa dispõe de algumas ações tanto de cunho ambiental quanto de cunho social e sustentável. Sobre consciência, sustentabilidade e questões ambientais globais, quase todos os sujeitos que responderam o questionário proposto compartilham positivamente com as mesmas respostas, além de considerarem muito importante a prática pela empresa e a participação deles mesmos.

Assim, programas sociais, desenvolvimento sustentável, meio ambiente, comunidade, participação, conscientização, educação ambiental 
pode ser registrados pela responsabilidade e comprometimento do Supermercado Pão de Açúcar, contribuindo assim para a melhoria das condições ambientais do nosso planeta.

O supermercado não possui um Programa de Educação Ambiental elaborado. No entanto, o trabalho educativo, é feito através da realização de palestras e treinamentos, tornando, assim, efetiva a participação do maior número de funcionários que contribuíram com a pesquisa. As atividades de Educação Ambiental praticada pelos clientes e pela comunidade ao entorno, apesar de ter grande relevância, apresenta um caráter reduzido do meio ambiente.

O ensino de Geografia pode contribuir significativamente para a evolução no modo de vida e nas formas de trabalho. Um dos caminhos possíveis envolve a Educação Ambiental dos funcionários e colaboradores, levando em consideração também o contexto social dos mesmos, perpetuando-se para a família e gradualmente para a sociedade em geral, através de uma herança cultural e de uma nova perspectiva para a maneira de pensar o homem como parte do meio ambiente.

A Educação Ambiental e a Geografia são de fundamental importância para a prática cidadã na atualidade, sendo assim, fazendo uma relação entre ambas, pode-se dizer que a Geografia permite o conhecimento da realidade social, econômica, cultural e ambiental, dando contribuição fundamental, para que a sociedade possa compreender e desenvolver uma consciência crítica sobre a problemática ambiental.

Quanto as dificuldades encontradas para a realização da pesquisa, fato marcante foi a falta de disponibilidade de tempo dos entrevistados, pois todos se encontravam em horário de trabalho. Contudo, foi possível a realização da pesquisa de campo e a obtenção de resultados suficientes para produzir a análise deste trabalho.

Portanto, é importante registrar que o tema proposto concede um conjunto de tensões, pois, por um lado foi direcionado à análise da Educação Ambiental para uma empresa privada, que tem como finalidade o lucro e, por outro, buscamos perceber em que medida essa empresa desenvolve práticas direcionadas à Educação Ambiental. Assim o desenvolvimento deste trabalho trouxe contradições, mas trouxe também as potencialidades em uma empresa 
privada que busca fazer sua parte pelo meio ambiente, através de suas práticas e Programas.

\section{REFERÊNCIAS}

ALMEIDA, Fernando. O bom negócio da sustentabilidade. Rio de Janeiro: Nova Fronteira, 2002.

BRASIL, Ministério do Meio Ambiente. Produção de Consumo Sustentável. Disponível em: http://www.mma.gov.br/. Acesso em: junho, 2015.

BRASIL. Política Nacional do Meio Ambiente - Lei Federal № 6938 de 1981. Disponível em:www.planalto.gov.br/ccivil_03/Leis/L6938.htm. Acesso em: junho, 2015.

BRASIL. Política Nacional de Educação Ambiental - Lei n. 9795, de 27 de abril de 1999. Diário Oficial da República Federativa do Brasil. Disponível em: www.planalto.gov.br/ccivil_03/leis//9795.htm. Acesso em: junho, 2015.

CARVALHO, Isabel Cristina de Moura. Em direção ao mundo da vida: interdisciplinaridade e educação ambiental/Conceitos para se fazer educação ambiental/Isabel Cristina de Moura Carvalho. - Brasília: IPE Instituto de Pesquisas Ecológicas, 1998. 101f. : il. ; $30 \mathrm{~cm}$, - (Cadernos de educação ambiental; 2)

GONÇALVES, Carlos Walter Porto. Os descaminhos do meio ambiente. São Paulo, 2 ed., Contexto 1990.

GUIMARÃES, Mauro. A dimensão ambiental na educação. São Paulo: Papirus, 1995.

GIL, Antonio Carlos. Gestão de pessoas: enfoque nos papéis profissionais. São Paulo: Atlas, 2002.

WOUTERLOOD, Cintia Soledad. Educação Empresarial na Cia.

Distribuidora de Gás - CEG, Rio de Janeiro. VI Congresso Nacional de Excelência em Gestão: energia, inovação, tecnologia, e complexidade para a gestão sustentável. Niterói, RJ, Brasil, 2010. Disponível em:

httpllwww.excelenciaemgestao.org \Acesso em: setembro, 2015.

LEÃO, Ana Lúcia Carneiro, SILVA, Lúcia Maria Alves. Fazendo Educação Ambiental. 4. ed. Recife: $\mathrm{CPRH}, 1999$.

LEFF, Enrique. Saber ambiental: sustentabilidade, racionalidade, complexidade, poder; tradução de Lúcia Mathilde Endlick Orth. 7 ed. Petrópolis, RJ: vozes, 2009. 
LIMA, Maria Jose Araújo. Ecologia humana: realidade e pesquisa. Petrópolis, RJ: vozes, 1984.

MOREIRA, Ruy. O que é Geografia? 2ª ed. São Paulo: Brasiliense, 2002, p. 113.

MOTTA, Márcio Jardim. A educação ambiental nas empresas e o Sistema de Gestão Ambiental, 2010. Disponível em: http://www.ietec.com.br/. Acesso em: junho, 2015.

OLIVEIRA, Alfredo Almeida Pino de. Análise documental do processo de capacitação dos multiplicadores do projeto "Nossas crianças: Janelas de oportunidades" no município de São Paulo à luz da Promoção da Saúde. 2007. 210 f. Dissertação (Mestrado em Enfermagem em Saúde Coletiva) Escola de Enfermagem, Universidade de São Paulo, São Paulo, 2007.

PEDRINI, Alexandre de Gusmão. Educação ambiental empresarial no Brasil. São Carlos: Rima, 2008.

PEDRINI, A. G. (Org.). Introdução Educação Ambiental Empresarial no Brasil, São Paulo: Rima Editora, 2008.

RELATÓRIO PRÊMIO FGV -. Responsabilidade Social no Varejo. EAESP, 2003.

ROOS, Alana; BECKER, Elsbeth Leia Spode. Educação ambiental e sustentabilidade. Revista Eletrônica em Gestão, Educação e Tecnologia Ambiental. REGET/UFSM. v(5), n5, p. 857 - 866, 2012.

SANSOLO, D. G.; CAVALHEIRO, F. Geografia e Educação Ambiental. In: SANTOS, J. E.; SATO, M. A Contribuição da Educação Ambiental à Esperança de Pandora. 3 ed. São Carlos: RiMa, 2006. 